\title{
At What Age Threshold does the Decline in Semen Parameters Begin?
}

\author{
Mehmet Kutlu Demirkol ${ }^{1}$, Osman Barut ${ }^{1}$, Neslihan Temiz Dogan², Mustafa Bilal Hamarat ${ }^{3}$ and Sefa Resim $^{1}$ \\ ${ }^{1}$ Department of Urology, Faculty of Medicine, Kahramanmaras Sutcu Imam University, Kahramanmaras, Turkey \\ ${ }^{2}$ Andrology Laboratory, Department of Urology, Faculty of Medicine, Kahramanmaras Sutcu Imam University, Kahramanmaras, Turkey \\ ${ }^{3}$ Department of Urology, Konya Health Application and Research Centre, Health Sciences University, Konya, Turkey
}

\begin{abstract}
Objective: To analyse changes in semen parameters according to different age groups in men presenting to an infertility clinic, and determine the age threshold for decline in semen quality.

Study Design: Observational study.

Place and Duration of Study: Andrology Laboratory, Department of Urology, Kahramanmaraş Sütçü İmam University, Turkey, from January 2018 to December 2019.

Methodology: Semen analysis records of infertile men, who were referred to Andrology Laboratory, were retrospectively evaluated. The age groups were categorised as 20-29, 30-34, 35-39, 40-44, and 45-55 years. Each group was completed to 100 semen samples retrospectively and sequentially without any preferences. The differences of semen parameters between age groups were analysed with the one-way ANOVA test. Linear relationship was checked by ANOVA.

Results: The mean age of 500 patients was $37.18 \pm 8.11$ years. While no linear relationship was observed in semen volume, concentration, and total sperm count with age $(p=0.133, p=0.290$ and $p=0.261$, respectively). A linear decline was observed in progressive motility, vitality, and morphology parameters with advancing age (all, $p<0.001$ ). In linear contrast analysis according to the $20-29$ age group; significant decline in progressive sperm motility, morphology, and vitality started and continued in the 35-39 age group (all, p<0.001).

Conclusion: With advancing age, a significant linear decrease in sperm motility, morphology and vitality was observed in infertile men. This significant decline in sperm motility, morphology and vitality continues at age 35 and over. Therefore, infertile men who plan to postpone paternity should consider the age factor.
\end{abstract}

Key Words: Aging, infertility, Paternal age, Semen analysis, Sperm.

How to cite this article: Demirkol MK, Barut O, Dogan NT, Hamarat MB, Resim S. At What Age Threshold does the Decline in Semen Parameters Begin?. J Coll Physicians Surg Pak 2021; 31(01):4-7.

\section{INTRODUCTION}

Today, couples plan to have children at a later age due to reasons such as increasing life expectancy, advanced age of marriage, career and socio-economic factors. In a recent study conducted in the USA, it was shown that the age of fatherhood has increased in the last 44 years and the average age of father has increased from 27.4 to 30.9 years. ${ }^{1}$

Since spermatogenesis continues until the advanced ages, male reproductive functions do not end suddenly as in women. However, with aging, degenerative changes occur in the germinal epithelium, causing a decrease in the number and function of Leydig cells. Thus, testosterone level decreases and spermatogenesis is affected. ${ }^{2,3}$

Correspondence to: Dr. Mehmet Kutlu Demirkol, Department of Urology, Faculty of Medicine, Kahramanmaras Sutcu Imam University, Kahramanmaras, Turkey

E-mail: kutludemirkol@hotmail.com

Received: November 24, 2020; Revised: December 28, 2020;

Accepted: January 06, 2021

DOI: https://doi.org/10.29271/jcpsp.2021.01.4
Studies have been conducted around the world showing the downward trend in semen parameters compared to the past years. ${ }^{4,5}$ Recently, studies have focused on the age factor and investigated age-related decreases in semen parameters. However, it was observed that the effects of male age on semen parameters were different. ${ }^{6-9}$ As a general trend in age-related studies, while semen volume, normal morphology and progressive motility decreases with age, sperm concentration has an inconsistent relation. ${ }^{10}$ In the literature, there are also different data about the threshold ages of onset of semen parameters to decline..$^{8,11,12}$ In addition, there is no study analysing the relationship between age and semen parametersinTurkishmen.

In this study, it was aimed to analyse the changes in semen parameters between the age ranges of men who applied to the infertility clinic and to determine the age threshold at which the change begins.

\section{METHODOLOGY}

In this observational study, the semen analysis records of infertile men, who were referred to the Andrology Laboratory of Kahramanmaraş Sütçü Imam University between January 2018 and December 2019 were reviewed. 
Table I: Comparison of the mean of semen parameters in different age groups.

\begin{tabular}{|c|c|c|c|c|c|c|}
\hline $\begin{array}{l}\text { Age groups } \\
\text { (year) }\end{array}$ & $\begin{array}{l}\text { Volume } \\
\text { (mL) }\end{array}$ & $\begin{array}{l}\text { Concentration } \\
\left(\times 10^{6} / \mathrm{mL}\right)\end{array}$ & $\begin{array}{c}\text { Total sperm count } \\
\qquad\left(\times 10^{6}\right)\end{array}$ & $\begin{array}{c}\text { Progressive motility } \\
(\%)\end{array}$ & $\begin{array}{l}\text { Vitality } \\
\text { (\%) }\end{array}$ & $\begin{array}{c}\text { Normal } \\
\text { morphology } \\
(\%)\end{array}$ \\
\hline $20-\left[29^{a}\right.$ & $3.06 \pm 1.31$ & $34.50 \pm 21.85$ & $108.04 \pm 91.03$ & $20.78 \pm 8.07^{c e}$ & $65.63 \pm 6.55$ cde & $1.34 \pm 1.54$ cde \\
\hline $30-34^{b}$ & $3.30 \pm 1.52$ & $36.53 \pm 23.62$ & $117.66 \pm 88.72$ & $20.28 \pm 7.47^{e}$ & $65.14 \pm 6.28$ cde & $1.33 \pm 1.65 \mathrm{cde}$ \\
\hline $35-39^{c}$ & $3.40 \pm 1.70$ & $28.07 \pm 20.31^{\mathrm{e}}$ & $88.18 \pm 66.06^{e}$ & $17.15 \pm 9.28^{a}$ & $61.25 \pm 11.07 \mathrm{ab}$ & $0.71 \pm 1.04 \mathrm{ab}$ \\
\hline $40-44^{d}$ & $3.37 \pm 1.85$ & $33.95 \pm 24.76$ & $108.92 \pm 96.52$ & $17.10 \pm 10.27$ & $61.00 \pm 8.89 a b$ & $0.70 \pm 1.10 \mathrm{ab}$ \\
\hline $45-55^{e}$ & $3.43 \pm 2.11$ & $40.06 \pm 29.24^{c}$ & $130.07 \pm 109.56^{c}$ & $16.53 \pm 9.46^{\mathrm{ab}}$ & $60.95 \pm 9.81^{a b}$ & $0.69 \pm 0.98 \mathrm{ab}$ \\
\hline $\mathrm{p}$ & 0.543 & 0.011 & 0.025 & 0.001 & $<0.001$ & $<0.001$ \\
\hline
\end{tabular}

Table II: Linear contrast analysis of semen parameters according to age groups.

\begin{tabular}{|c|c|c|c|c|c|c|}
\hline$z$ & $\begin{array}{l}\text { Volume } \\
\text { (mL) }\end{array}$ & $\begin{array}{c}\text { Concentration } \\
\left(\times 10^{6} / \mathrm{mL}\right)\end{array}$ & Total sperm count $\left(\times 10^{6}\right)$ & $\begin{array}{c}\text { Progressive motility } \\
(\%)\end{array}$ & $\begin{array}{c}\text { Vitality } \\
(\%)\end{array}$ & $\begin{array}{c}\text { Normal morphology } \\
(\%)\end{array}$ \\
\hline $20-29$ & $3.06 \pm 1.31$ & $34.50 \pm 21.85$ & $108.04 \pm 91.03$ & $20.78 \pm 8.07$ & $65.63 \pm 6.55$ & $1.34 \pm 1.54$ \\
\hline $30-34$ & $3.30 \pm 1.52$ & $36.53 \pm 23.62$ & $117.66 \pm 88.72$ & $20.28 \pm 7.47$ & $65.14 \pm 6.28$ & $1.33 \pm 1.65$ \\
\hline $35-39$ & $3.40 \pm 1.70$ & $28.07 \pm 20.31$ & $88.18 \pm 66.06$ & $17.15 \pm 9.28 *$ & $61.25 \pm 11.07 *$ & $0.71 \pm 1.04 *$ \\
\hline $40-44$ & $3.37 \pm 1.85$ & $33.95 \pm 24.76$ & $108.92 \pm 96.52$ & $17.10 \pm 10.27^{*}$ & $61.00 \pm 8.89 *$ & $0.70 \pm 1.10 *$ \\
\hline $45-55$ & $3.43 \pm 2.11$ & $40.06 \pm 29.24$ & $130.07 \pm 109.56$ & $16.53 \pm 9.46 *$ & $60.95 \pm 9.81 *$ & $0.69 \pm 0.98 *$ \\
\hline $\mathrm{p}$ linear & 0.133 & 0.290 & 0.261 & $<0.001$ & $<0.001$ & $<0.001$ \\
\hline
\end{tabular}

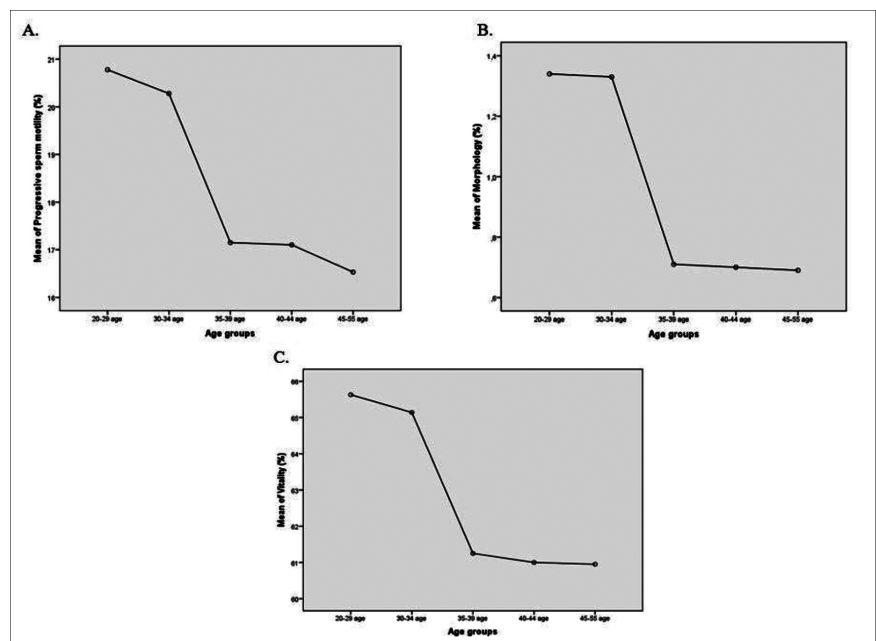

Figure 1: The mean progressive motility, vitality and morphology curves for age groups.

The study was conducted in accordance with the latest version of the Helsinki Declaration and was approved by the Institutional Review Board.

Semen samples with azoospermia and severe oligozoospermia $(<1 \mathrm{million} / \mathrm{ml}$ ) were not included in the study. The most recent semen sample of those, who had more than one semen sample, was included in the study. Since semen samples in the 20-24 age groups and 50-55 age groups were insufficient, these categories were combined with the 25-29 and 45-49 age groups, respectively, to obtain the following age groups: 20-29, 30-34, 35-39, 40-44 and 45-55 years. Each group was completed to 100 semen samples retrospectively and sequentially without any selection.

After 3-5 days of sexual abstinence, semen samples were collected by masturbation in the laboratory and analysis was performed according to the latest WHO criteria. ${ }^{10}$ All samples were allowed to liquefy at $37^{\circ} \mathrm{C}$ for at least 20 minutes and analysed within 30-60 minutes following liquefaction. The data of semen samples, such as semen volume, sperm concentration, total sperm count, percentage of progressive motile sperm, percentage of viable sperm (vitality) and percentage of sperm with normal morphology were measured and recorded. Standard reference values were determined as $1.5 \mathrm{~mL}$ for semen volume, $15 \times 10^{6} / \mathrm{mL}$ for sperm concentration, $39 \times 10^{6}$ for total sperm count, $32 \%$ for progressive motility, $58 \%$ for vitality and $4 \%$ for normal morphology.

SPSS software (version 22.0, IBM, USA) was used for data analysis. Continuous variables were given as mean \pm standard deviation (S.D), and categorical data as number (\%). The differences between the mean semen parameters of age groups were analysed by one-way ANOVA test. Tamhane's T2 was used for paired comparisons in post-hoc analysis as equal variances are not assumed. The linear contrast test of ANOVA was used to analyse whether there was a linear relationship in the parameters that found statistically different. Statistical significance was defined as $p<0.05$.

\section{RESULTS}

The mean age of 500 patients was $37.18 \pm 8.11$ years. Out of the total patients, 104 (20.8\%) had oligozoospermia, 462 (92.4\%) had asthenozoospermia and 476 (95.2\%) had teratozoospermia. The numbers of people with normal semen volume and vitality were 435 (87\%) and 416 (83.2\%), respectively. The mean semen volume, concentration, total sperm count, percentage of progressive motility, vitality, and normal morphology of all patients were $3.31 \pm 1.72,34.62 \pm 24.31$, $110.57 \pm 92.14,18.37 \pm 9.11,62.79 \pm 8.94$ and $0.95 \pm 1.32$, respectively. 
There was a significant difference in sperm concentration, total number, advanced motility, vitality, and morphology parameters of age groups. On the other hand, the mean semen volumes of the age groups were not different $(p=0.543)$ (Table I).

A linear decline was observed in progressive motility, vitality, and morphology parameters with advancing age $(p<0.001$, for all three) (Table II). It was observed that this linear decrease in all three parameters started and continued in the 35-39 age group (Figure 1). From the other side, when sperm concentration and total count parameters, which differed significantly in ANOVA, were re-examined with the linear contrast analysis, it was seen that there was no linear relationship between them. ( $p=0.290$ and $p=0.261$, respectively).

\section{DISCUSSION}

Many studies have shown that semen parameters are negatively affected by aging. However, the results show that semen parameters are affected differently. ${ }^{7,9,12-15}$ In this study, there was no difference between age groups and semen volume, but a significant difference was observed in sperm concentration, total number, motility, vitality and morphology parameters. However, only progressive motility, vitality and morphology parameters decreased linearly with advancing age. Kumar et al. found that mean values of semen volume, total sperm count, sperm motility, and morphology showed a steady decline with increasing age in their study. ${ }^{14} \mathrm{~A}$ systematic literature review, meta-regression and meta-analysis study with small-to-medium effects power and high level of scientific evidence also substantially support the findings of this study. ${ }^{10}$ In this review, it was observed that low semen volume, total sperm count, percentages of motility, progressive motility, normal sperm and nonfragmented cells were associated with advanced age, but age did not have a consistent effect on sperm concentration. On the other side, a study evaluating semen quality in 140 infertile men concluded that advancing age is associated with a decrease in semen volume and vitality, and an increase in sperm concentration, but the decrease in motility and morphology is not statistically significant. ${ }^{15}$

In several reviews, the most consistent findings among studies is the decline in semen volume in the aged males. ${ }^{10,16,17}$ However, we could not find a relationship between increased age and semen volume in this study.

Although there was a significant difference between the age groups in terms of sperm concentration and total sperm count, it was noted that there was no significant decrease in these parameters with advancing age. A previous study analysis also could not detect the effect of age on sperm concentration or total sperm count. ${ }^{18}$ In addition, a review summarised six studies showing little or no correlation between age and sperm concentration. ${ }^{17}$ Moreover, in another systematic review and meta-analysis, It was emphasised that the male age does not have a consistent effect on sperm concentration. ${ }^{10}$ On the other hand, many recent studies have shown that age is negatively correlated with sperm concentration. ${ }^{8,9,12,14}$
Among the sperm parameters, the highest decrease with age is generally in sperm motility. In this study, it is shown that there is a significant decrease in progressive motility in the 35-39 age group compared to the 20-29 age group, and this trend continues in older age groups. Several reviews, evaluating methodological strong studies, have proven that advancing age has a negative effect on sperm motility. ${ }^{10,17}$ In a recent study, it is revealed that males aged $31+$ years were more likely to have decreased sperm motility, and men over 50 years of age, compared to age 21-30, had 11.91 times impaired progressive sperm motility. ${ }^{12}$ Another study found that all sperm motility parameters began to decline at the age of 43 years. ${ }^{8}$

In addition to sperm motility, it is found in this study that morphology is also affected by increasing male age. Likewise, it was observed that the first significant decrease in morphology started and continued in the 35-39 age group. In a review examining the relationship between sperm morphology and age, it was compiled that nine out of 14 studies had a decrease in normal sperm percentage associated with age, and five studies did not show a relationship. ${ }^{17}$ Furthermore, in the methodologically stronger systematic literature review and meta-analysis conducted by Johnson et al., male age was shown to be associated with a low percentage of normal sperm. ${ }^{10}$ Lastly, while the percentage of normal sperm started to decrease at the age of 40-44 in one of two recent studies, the other study found that the maximum fall in morphology was noted after 35 year of age..$^{8,14}$

Finally, sperm vitality decreases with advancing age and this decrease begins in the 35-39 age group. A similar finding is supported by a previous study, where researchers found that vitality was negatively correlated to age, and age cut-off value was 41.5 years for vitality. ${ }^{19}$

Due to the retrospective nature of this study, the effects of confounding factors that could affect semen parameters, such as occupational exposure, smoking, alcohol consumption, obesity and medication, could not be investigated. Several studies have shown that these factors affect semen parameters. $^{20,21}$ Therefore, if a prospective study is planned by including normal fertile men as a control group and analysing the effect of these confounding factors, the effect of age on semen parameters can be more clearly evaluated.

\section{CONCLUSION}

The findings of this study support that aging negatively affects semen parameters, also in infertile men. With advancing age, a significant linear decrease in sperm motility, morphology and vitality was observed in infertile men; while there is no linear decline in semen volume, sperm concentration and total sperm count.

This significant decline in sperm motility, morphology and vitality continues at age 35 and over. Therefore, infertile men who plan to postpone paternity should consider the age factor.

\section{ETHICAL APPROVAL:}

All procedures performed in this study involving human participants were in accordance with the ethical standards of the Institutional 
Research Committee, and with the 1964 Helsinki Declaration and its later amendments or comparable ethical standards. This study was approved by Kahramanmaraş Sütçü İmam University Medical Ethics Committee. (Ref No. 2010/10 Date: 27.05.2020).

\section{PATIENTS' CONSENT:}

Since it was designed as a retrospective study, the data were collected from the hospital archives after approval of the Ethics Committee.

\section{CONFLICT OF INTEREST:}

Authors declared no conflict of interest.

\section{AUTHORS' CONTRIBUTION:}

MKD: Conception of the work, analysis or interpretation of data for the work, discussion and literature review.

OB: Data analysis, results, and discussion.

NTD: Literature search, analysis and interpretation of data.

$\mathrm{MBH}$ : Conception and design, acquisition of data.SR: Critical revision of the manuscript.

SR: Critical revision of the manuscript.

\section{REFERENCES}

1. Khandwala YS, Zhang CA, Lu Y, Eisenberg ML. The age of fathers in the USA is rising: An analysis of 168867480 births from 1972 to 2015. Hum Reprod 2017; 32(10): 2110-6. doi: 10.1093/humrep/dex267.

2. Wang C, Leung A, Sinha-Hikim AP. Reproductive aging in the male brown-Norway rat: A model for the human. Endocrinol 1993; 133(6):2773-81. doi: 10.1210/endo. 133.6.8243304.

3. Johnson L. Spermatogenesis and aging in the human. J Androl 1986; 7(6):331-54. doi: 10.1002/j.1939-4640. 1986.tb00943.x.

4. Siqueira S, Ropelle AC, Nascimento JAA, Fazano FAT, Bahamondes LG, Gabiatti JR, et al. Changes in seminal parameters among Brazilian men between 1995 and 2018. Sci Rep 2020; 10(1):6430. DOI: 10.1038/s41598- 020-63468-9

5. Butt F, Akram N. Semen analysis parameters: Experiences and insight into male infertility at a tertiary care hospital in Punjab. J Pak Med Assoc 2013; 63(5):558-62.

6. Rehan N. Semen characteristics of fertile Pakistani men. J Pak Med Assoc 1994; 44(3):62-4.

7. Winkle T, Rosenbusch B, Gagsteiger F, Paiss T, Zoller N. The correlation between male age, sperm quality and sperm DNA fragmentation in 320 men attending a fertility center. J Assist Reprod Genet 2009; 26(1): 41-6. doi: 10.1007/s10815-008- 9277-3.

8. Stone BA, Alex A, Werlin LB, Marrs RP. Age thresholds for changes in semen parameters in men. Fertil Steril 2013; 100(4):952-8. doi: 10.1016/j.fertnstert.2013.05.046.

9. Colasante A, Minasi MG, Scarselli F, Casciani V, Zazzaro V, Ruberti $A$, et al. The aging male: Relationship between male age, sperm quality and sperm DNA damage in an unselected population of 3124 men attending the fertility centre for the first time. Archives 2019; 90(4):254-9. doi.org/ 10.4081/aiua.2018.4.254.

10. Johnson SL, Dunleavy J, Gemmell NJ, Nakagawa S. Consistent age-dependent declines in human semen quality: A systematic review and meta-analysis. Ageing Res Rev 2015; 19:22-33. doi: 10.1016/j.arr.2014.10.007.

11. Zhu QX, Meads C, Lu ML, Wu Q, Zhou WJ, Gao ES. Turning point of age for semen quality: a population-based study in Chinese men. Fertil Steril 2011; 96(3):572-6. doi: 10.1016/ j.fertnstert.2011.06.058.

12. Pino V, Sanz A, Valdés N, Crosby J, Mackenna A. The effects of aging on semen parameters and sperm DNA fragmentation. JBRA Assisted Reproduction 2020; 24(1): 82-6. doi: 10.5935/ 1518-0557.20190058.

13. Salmon-Divon M, Shrem G, Balayla J, Nehushtan T, Volodarsky-Perel A, Steiner $\mathrm{N}$, et al. An age-based sperm nomogram: the McGill reference guide. Hum Reprod 2020; 35(10):2213-25. doi: 10.1093/humrep/deaa196.

14. Kumar N, Singh AK, Choudhari AR. Impact of age on semen parameters in male partners of infertile couples in a rural tertiary care center of central India: A cross-sectional study. Int J Reprod Biomed 2017; 15(8):497-502.

15. Brahem S, Mehdi M, Elghezal H, Saad A. The effects of male aging on semen quality, sperm DNA fragmentation and chromosomal abnormalities in an infertile population. J Assist Reprod Genet 2011; 28(5):425-32. doi: 10.1007/s10815011-9537-5.

16. Mazur DJ, Lipshultz LI. Infertility in the aging male. Curr Urol Rep 2018; 19(7):54. doi: 10.1007/s11934-018- 0802-3.

17. Kidd SA, Eskenazi B, Wyrobek AJ. Effects of male age on semen quality and fertility: A review of the literature. Fertil Steril 2001; 75(2):237-48. doi: 10.1016/s0015-0282(00) 01679-4.

18. Sloter E, Schmid TE, Marchetti F, Eskenazi B, Nath J, Wyrobek AJ. Quantitative effects of male age on sperm motion. Hum Reprod 2006; 21(11):2868-75. doi: 10.1093/ humrep/del250.

19. Verón GL, Tissera AD, Bello R, Beltramone F, Estofan G, Molina RI, et al. Impact of age, clinical conditions, and lifestyle on routine semen parameters and sperm kinematics. Fertil Steril 2018; 110(1):68-75.e4. doi: 10.1016/j.fertnstert.2018.03.016.

20. García-Ferreyra J, Luna D, Villegas L, Romero R, Zavala P, Hilario $R$, et al. High aneuploidy rates observed in embryos derived from donated oocytes are related to male aging and high percentages of sperm DNA fragmentation. Clin Med Insights Reprod Health 2015; 9:21-7. doi: 10.4137/CMRH. S32769.

21. Oliveira JBA, Petersen CG, Mauri AL, Vagnini LD, Renzi A, Petersen $B$, et al. Association between body mass index and sperm.quality and sperm DNA integrity. A large population study. Andrologia 2018; 50(3). doi: 10.1111/ and.12889. 